\title{
Students' Approaches to Learning: Validating Study Processes Questionnaire for Use in Congolese Setting
}

\author{
Madeleine Kapinga-Mutatayi ${ }^{1}$, Pierre Mukendi ${ }^{2}$ and Jan Elen ${ }^{3}$ \\ ${ }^{1}$ KULeuven, Centre for Instructional Psychology and Technology, 3000, Leuven Belgium; Unikin, Faculté de \\ Psychologie et Sciences de l'éducation. \\ ${ }^{2}$ Unikin, Faculté de Psychologie et Sciences de l'Education, Kinshasa/DRCongo. \\ ${ }^{3}$ KULeuven, Centre for Instructional Psychology and Technology, 3000, Leuven/ Belgium. \\ Email: madokapi@yahoo.fr; madeleine.kapingamutatayi@student.kuleuven.be, pierre_mukendi@yahoo.fr, \\ Jan.Elen@ppw. kuleuven. be
}

\begin{abstract}
Learning outcomes are mostly determined by students' approaches to learning (SAL). The Study Process Questionnaire (SPQ) is one of the most used instruments assessing SAL. Researchers from various contexts have either validated or used the SPQ. A few studies in African contexts have investigated its psychometrics properties or used it as such. However, none of them - to the best of our knowledge -stem from a French African context. The current paper fills this gap by exploring the reliability and the validity of the R-SPQ-2F (SPQ revised version) in a Congolese setting. In line with the original findings, the main scales (Deep and Surface) were found to be acceptably reliable whereas the subscales reliability was questioned. At the dimension level, the construct validity was confirmed though items-based analysis showed disappointing results. The results also revealed a positive correlation between both main scales. Findings are discussed for further investigations.
\end{abstract}

Key words: Learning approaches, Instruments adaptation, Reliability and validity, Confirmatory factor analysis

\section{Introduction}

A variety of variables influence learning outcomes in higher education. It is now generally accepted that learning outcomes are predominantly determined by student's activities (Driscoll, 2005; Elen \& Lowyck, 2000; Gijbels, Coertjens, Vanthournout, Struyf, \& Van Petegem, 2009; Richey, Klein, \& Tracey, 2011). Students' approaches to learning (SAL) is an attempt to capture these activities for a better understanding of learning processes. SAL has been shown to be related to personal and contextual variables (Richardson, 1994; Säljö, 2004). Direct as well as indirect effects of SAL on students' learning outcomes were evidenced in the literature (Asikainen, Parpala, Lindblom-Ylänne, Vanthournout, \& Coertjens, 2014; Entwistle \& Peterson, 2004). Most studies on learning approaches have used AngloSaxon instruments. The SPQ as well as its different versions is widely used to assess SAL. Initial studies in Africa have confirmed that the SPQ could be used as a valid instrument to assess SAL in this specific setting (Mogre \& Amalba, 2014; Watkins \& Mboya, 1997). However, investigations with respect to psychometric properties of this instrument have - to the best of our knowledge - never been systematically conducted in African French speaking countries. Given the lack of such studies, the current paper explores the reliability as well as the construct validity of the R-SPQ-2F in a Congolese context. In so doing, this research represents one of the responses to the ongoing Congolese government concerns with respect to the improvement of the higher education system (Minesu, 2011).

\section{Theoretical Background}

\subsection{Conceptualization and Measure of Students' Approaches to Learning}

Students' approaches to learning (SAL) have been widely explored in the literature (Biggs, Kember, \& Leung, 2001; Entwistle \& Peterson, 2004; Entwistle, Tait, \& McCune, 2000) and were conceptualized in terms of a dynamic process describing students' learning strategies and motives at a particular moment. 
As such, a learning approach is neither a stable trait nor a static characteristic of the learner (Bliuc, Ellis, Goodyear, \& Hendres, 2011a, 2011b; Gijbels et al., 2009; Säljö, 2004). Empirical findings furthermore confirmed that SAL is affected by students' perceptions of learning environments (Biggs et al., 2001). Researchers generally distinguish two main approaches, i.e. deep and surface approaches with their equivalence in terms of meaning-oriented and reproduction-oriented approaches (Biggs et al., 2001; Entwistle et al., 2000; Marton \& Säljö, 1976, 1984). In the former, more attention is given to understanding by referring to prior information, making sense of ideas, establishing relations between facts. In contrast, a surface approach emphasizes memorization, repetition, rote learning, minimal effort and engagement, feeling of constraints, and fulfillment of task requirements for assessment purposes (Entwistle \& Peterson, 2004; Marton \& Säljö, 1976). Researchers also seem to agree about a third approach, termed achieving or strategic. This one refers to the student management of time and organization of studies to maximize marks (Biggs, 1987; Entwistle \& Ramsden 1983).

Along with the conceptualization of SAL, there has been the subsequent development of inventories assessing the way students go about their learning. Amongst instruments to assess SAL, the SPQ (Study process questionnaire) and the ASI (Approaches to studying inventory) as well as their revised versions are the most used (Biggs, 1987; Biggs et al., 2001; Entwistle \& Ramsden, 1983; Richardson, 2004). The SPQ is composed of three scales labelled deep, surface and achieving or strategic approaches, each with two sub-scales: deep-motive, deep-strategy, surface motive, surface strategy, achieving motive and achieving strategy (Biggs, 1987). The deep and surface scales relate to the meaning and reproducing orientations respectively. The achieving approach on the other hand relates to the search for highest marks.

The structure of the SPQ was brought into question by some researchers (Kember \& Gow, 1990; Kember \& Leung, 1998; Richardson, 1994). Kember and Leung (1998) for instance tested the validity of the SPQ. Their results, based on confirmatory factor analysis, showed that the instrument is best described by a two-factor model. In this model, the subscales achieving motive and achieving strategy load on both the deep and the surface scale. Subsequent studies have also confirmed these results (Kember \& Gow, 1990; Kember, Wong, \& Leung, 1999). In addition, Richardson (1994) qualified the achieving approach to be quite ambiguous compared to deep and surface approaches.

More than a decade later, there was a need for a short and simple instrument assessing SAL. Biggs and colleagues (2001) worked to supply teachers and staff with such an instrument. In this process, they elaborated new items but also selected several items from the SPQ that were either reworded or used in their initial form. Overall, 43 items were included in the refinement process. The questionnaire of 43 items was completed by health science students from a Hong Kong University. Students responded on a 5 point Likert scale from 'always true of me' to 'only rarely true of me'.

Cronbach's alpha was used to assess the reliability of data based on 229 filled questionnaires. Items negatively affecting the reliability were reexamined. In the same perspective, a confirmatory factor analysis was also performed. To decide about the deletion of items contributing less to the factors, the designers relied either on the combination of regression coefficients and errors terms (high regression coefficients and low errors terms characterize items that contribute more to a dimension) or on the association of multivariate Langrange Multiplier tests (LM) and Wald tests. They investigated respectively the addition and the deletion of paths in the hypothesized model (Hu \& Bentler, 1998, 1999; Weston \& Gore Jr., 2006). Both processes improved the model and reduced the number of items. Overall, an instrument of two scales (deep and surface approaches), each with 10 items resulted from those procedures. Additionally, the motive and strategy subscales namely deep motive (DM), deep strategy (DS), surface motive (SM), and surface strategy (SS) each with 5 items were identifiable within each factor (Biggs et al., 2001).

This final version of the revised two factor study process questionnaire (R-SPQ-2F) was then completed by 495 undergraduate students from a Hong Kong University. The confirmatory factor analysis supported the assessment of the dimensionalities of four subscales. In effect, to avoid the type one and two errors, Biggs and colleagues (2001) have used the combination of the standardized root mean squared residual (SRMR) and the comparative fit index (CFI) as representing the two-index strategy (Hu \& Bentler, 1999). CFI values greater than .95 and SRMR less than .08 indicated a relatively good fit between the hypothesized model and the observed data (Biggs et al., 2001). Two complementary hypothesized models were tested. The first one at the items' level relates to four subscales as representing latent variables namely Deep motive (DM), Deep strategy (DS), Surface 
motive (SM), and surface strategy $(\mathrm{SS})$ and their corresponding five items as indicators. In the second model, items were parceled into the four subscales ( $\mathrm{dm}, \mathrm{ds}, \mathrm{sm}$, and ss) which were the indicators of the two main latent factors namely deep and surface approaches (DA and SA). The lowercase letters and uppercase letters were used to distinguish the observed variables from the latent factors. It seems worthwhile to notice that both models hypothesized deep and surface approaches correlation as being negative (Biggs, et al., 2001). The SRMR values of .058 and .015 relate to both models respectively whereas .904 and .992 correspond to their respective CFI. Although both models appear to be good, the fit of the second model was better than the first. Moreover, the reliability of .73 and .64 for deep and surface approach respectively were considered to be acceptable. The designers recommended the use of the simplest structure of two scales (deep and surface) each with 10 items to teachers. However, researchers might also look at the 4 subscales (Biggs et al., 2001).

\subsection{Validation and Use of SPQ and R-SPQ-2F in Different Contexts}

The same structure of instruments across cultures is one of the manifestations of cross-cultural validity (Parpala, Lindblom-Ylänne, Komulainen, \& Entwistle, 2013). The R-SPQ-2F was cross-culturally validated by Leung, Ginns, and Kember (2008). The aim of their study was to determine whether the same structure could be found in Western and Eastern contexts. So, Hong Kong and Australian students completed the R-SPQ-2F. Data were analyzed by the means of confirmatory factor analysis. Their findings described the two samples as using the same approaches to learning. So, the same structure was retrieved from both groups. Therefore, they confirmed their expectations. The instrument was validated in different countries. Gijbels, Van de Watering, Dochy and Van den Bossche's (2005) work for instance resulted in the Dutch version of the R-SPQ-2F whereas the work by Justicia, Pichardo, Cano, Berbén and De la Fuente (2008) produced the Spanish version of the same instrument. The studies mentioned above indicated that the latent structure of the R-SPQ-2F is best described by two factors. The translation of the instrument in different languages enabled its validation and use across contexts.

Investigations of Asian SAL have shown the emergence of the use of memorization with the intention to understand materials while - strictly speaking - there is no search for meaning in a surface approach (Kember, 1996; Richardson, 1994, 2004). Hence, researchers examined different combinations of both traditional approaches to learning. Kember and Gow (1990), for instance, referred to "narrow approaches" as characteristic of students who work on course materials step by step and whose understanding of materials is followed by memorization. Among factors entailing narrow approaches, students' limitations in English and their Confucian culture (Chan \& Rao, 2009) were noticed (Kember, 1996; Kember \& Gow, 1990). The term intermediate approach was also used to describe this combination of surface and deep approaches. From this perspective, Leung et al. (2008), using the RSPQ-2F, have demonstrated that Asian students adopted the intermediate approach more often than their Australian counterparts. Though they recognized that Western students also rely quite a bit on this approach, their argument was not sufficiently strong to contrast the assumption that the combination is an Asian specificity.

In a Japanese setting, Fryer, Ginns, Walker, and Nakao (2012) validated the R-SPQ-2F. The second Biggs et al. (2001) model based on item parceling technique (Clustering items into a package of subscales) fitted their data well. So, their results were consistent with Biggs et al.'s (2001) findings. However, and in contrast with previous research, their findings showed a positive correlation $(\mathrm{r}=.30)$ between surface and deep approaches to learning. They related these findings to a potential adoption of the intermediate approach. In that, they reinforced the doubts about the dichotomy view of SAL (Kember, 1996, 2000). Kember and Watkins (2010) suggested considering both deep and surface as complementary. Furthermore, an approach to learning exhibited by a student appears to be a contextdependent variable (Entwistle\& Peterson, 2004; Gijbels et al., 2009; Säljö, 2004).

In a Canadian setting, Coté, Graillon, Waddell, Lison and Noel (2006) used the back-translation process to produce the French version of the R-SPQ-2F at Université de Sherbrook (Coté, et al., 2006). To investigate SAL in a preclinical problem-based medical curriculum, 404 students in medicine (3 preclinical years) completed the French version of R-SPQ-2F. The exploratory factor analysis and the confirmatory factor analysis confirmed that 2 dimensions (deep and surface) underline the instrument. The reliability of both scales was tested by the means of Cronbach's alpha (.72 for deep and .70 for 
surface). Compared to the original findings, their surface scale was found to be more reliable. Moreover, the results based on the means, showed a significant use of surface approach to learning while a moderate use of deep approach was also noticed. On the other side, the ANOVA results revealed that a combination of deep and surface approaches to learning characterized students profiles across years of study. Coté and colleagues related such combinations to students' perceptions of the exam and the curriculum. In a similar way, other previous researchers have also confirmed the connection between SAL and their perceptions of the learning environments (Coertjens, Vanthournout, Lindblom-Ylänne, \& Postareff, 2016; Gijbels, Segers\&Struyf, 2008; Parpala et al., 2013).

Still in a French-speaking context, Pottier and colleagues (2008) analyzed SAL in relation to their problem-solving strategies, and their problem-solving performances. They used the Coté et al.'s French version of R-SPQ-2F. The $4^{\text {th }}$ year French students $(N=131)$ in medicine acted as participants. The Cronbach's alpha of .62 was considered to be acceptable for the instrument as a whole. Significantly, students used more deep than surface approaches to learning. In addition, a significant negative correlation between surface and deep scales $(\mathrm{r}=-.24)$ was noticed. Moreover, they observed a significant positive correlation between deep approaches to learning and the performances in one of the clinical problems. It seems important to notice that the French version of the instrument has - to the best of our knowledge- never been used in an African context.

A few investigations of SAL started in the African English speaking context in the 1990s. Naturally, researchers in this setting used the English version of the SPQ. The study by Meyer and Muller (1990) explored the relation between South African SAL and their perceptions of the learning context. The former was assessed by the means of ASI while the latter was measured through the Course Perceptions Questionnaire (CPQ). The unfolding analysis (mathematical technique) supported the graphical representation of SAL and their perceptions at the individual's level. Different patterns of relations emerged from their analysis. They revealed for instance, a firm association between deep perception and meaning orientation whereas the surface perception was fairly associated with the reproducing orientation. Similarly, Richardson's review in relation to the main scales assessing SAL, demonstrated that the deep approach or meaning orientation scale was found to be more consistent and generally associated with positive perceptions across contexts (Richardson, 1994, 2004).

Watkins and Mboya (1997) investigated the reliability and the validity of the LPQ (School version of the SPQ) for black South African students. The LPQ was administered to 327 black students in a secondary school. Cronbach's alphas varying from .39 to .65 were reported. The exploratory factor analysis revealed that two factors underlined the structure of the whole instrument. Their results in terms of reliability and validity are similar to Biggs's (1987) findings with Hong Kong and Australian samples. However, black South African students' scores on all the subscales were higher than their Hong Kong and Australian counterparts. Watkins and Mboya (1997) concluded that the instrument was valid and moderately reliable. They called for further qualitative studies to deepen understanding in relation to individual differences in terms of approaches to learning. They also questioned the belief that students from the South side of the world would exhibit more a surface approach than those from more developed countries (Watkins \& Mboya, 1997).

Recently, Mogre and Amalba (2014) assessed the reliability and validity of the R-SPQ-2F in a Ghanaian context. 189 students from the second to the fourth year in medicine completed the questionnaire. The DA and SA had Cronbach's alpha of .80 and .76 while the subscales (DM, DS, SM and SS) yielded the following values $.57, .71, .68$, and .58 respectively. The exploratory factor analysis results showed that 2 factors underline the structure of the instrument. Therefore, the instrument was considered to be reliable and valid to assess SAL in the preclinical's context and useful for the subSaharan African setting. One year later, they used theR-SPQ-2F to assess SAL in medicine in relation to their age, gender and year of study. The results revealed that only students' age was associated with their approaches to learning (Mogre \& Amalba, 2015).

In sum, most studies described here have tested either the SPQ or the R-SPQ-2F in Anglo-Saxon, European, Asian and African English speaking contexts. It appears relevant to scrutinize SAL in various contexts given the current change in the higher education population around the world (Manikutty, Anuradha, \& Hansen, 2007; Schendel, 2014). In addition, several researchers have called for the validation of the instrument in various cultural contexts (Fryer et al., 2012; Leung et al., 2008). Considering on the one hand the appalling deficit of studies on SAL in African French speaking countries, and on the other hand, the lack of valid instruments to engage with this framework, this 
paper intends to fill the gap by investigating the reliability and the validity of the R-SPQ-2F in a Democratic Republic of Congo's (DRC) setting. To this end, it seems realistic to answer the following questions: 'Are the R-SPQ-2F scales reliable in a DRC context?', 'What structure underlies the R-SPQ2F-based data in the Congolese context?', 'Which of the R-SPQ-2F theoretical models best fit Congolese data?'

\section{Method}

\subsection{Overall Design}

This study is based on the attempt to adapt the R-SPQ-2F for future use in a Congolese setting. Confirmatory factor analysis was used to assess the goodness of model fit and the reliability was tested through Cronbach's alpha.

\subsection{Participants}

Cognitive interviews were done at the initial stage of this study to check how understandable each statement was (Beatty \& Willis, 2007; Desimone \& Le Floch, 2004). Ten second year psychology students have answered the question 'how can you reformulate, say in other words this statement?' (Brancato et al., 2006). Their responses led to minor changes in the wording. For instance, the term 'syllabus' was replaced by 'Objectives', 'reading novel' by 'watching interesting movie', suggested reading by 'references list'. The next step consisted in administering this 'adapted questionnaire' with a sample of $1882^{\text {nd }}$ year management students from a Congolese University: Université de Kinshasa (Unikin).

\subsection{Instrument: Revised Two-factor Study Process Questionnaire (R-SPQ-2F)}

The R-SPQ-2F is made of both deep and surface scales as mentioned earlier (Biggs et al., 2001). The deep scale includes items like: 'I come to most classes with questions in mind that I want answering'. The surface scale contains items such as: 'I see no point in learning material which is not likely to be in examination' (Biggs et al., 2001). The responses to the statements are provided on the 5-point Likert scale from 1 (This item is never or rarely true of me) to 5 (This item is always or almost always true of me). The current study relies on the French version used by Pottier et al (2008).

\subsection{Procedures}

The R-SPQ-2F questionnaire was administered during course time. Two lecturers supervised the process. Participation was optional. More than $95 \%$ of students agreed to participate. There was no restriction in relation to the time. All the questionnaires were returned within an average of 20 minutes.

\subsection{Data Analysis}

The SPSS program was used to describe data and to test the reliability of scales and sub-scales. The assessment of scales dimensionality as well as the model goodness of fit was performed through AMOS software.

\subsubsection{Descriptive Statistics}

The students' responses, ranged from 1 (This item is never true) to 5 (This item is always true) were coded in SPSS. The score of each scale was obtained by the addition of its 10 items (Biggs et al., 2001). Therefore, 10 and 50 are respectively the lowest and the highest expected values. Descriptive statistics are displayed in table 1. 
Table 1. Scales statistics $(\mathrm{N}=188)$

\begin{tabular}{l|r|r|r|r|r}
\hline Scales & Mean & Std. Deviation (SD) & Maximum & Minimum & $\mathrm{r}$ \\
\hline Surface & 24.50 & 6.99 & 43 & 10 & \multirow{2}{*}{$609^{* *}$} \\
\hline Deep & 34.89 & 4.81 & 47 & 22 & .27 \\
\hline
\end{tabular}

** Correlation is significant at the 0.01 level (2-tailed).

When we examine different means and maximum values in table 1 , it appears that students have a general tendency to use more deep than surface approaches. Their scores on deep approach are higher than on surface approach scale. In addition, a significant positive Pearson's correlation in the last column $(\mathrm{r}=.609, \mathrm{p}=.000)$ shows that both scales are strongly interrelated.

\subsubsection{Internal Consistency and Unidimensionality of Subscales}

Various analyses were done to investigate the internal consistency and the structure of the instrument. Results are displayed in table 2 .

Table 2. Unidimensionality and Reliability of subscales

\begin{tabular}{l|l|l|l}
\hline Subscales / Indices & $\begin{array}{l}\text { SRMR } \\
(\text { Biggs })\end{array}$ & $\begin{array}{l}\text { CFI } \\
(\text { Biggs })\end{array}$ & $\begin{array}{l}\text { Alpha } \\
(\text { Biggs } \alpha)\end{array}$ \\
\hline Deep Motive DM & .03 & 1.000 & .28 \\
& $(.01)$ & $(.997)$ & $(.62)$ \\
\hline Deep Strategy DS & .03 & 1.000 & .59 \\
& $(.02)$ & $(.998)$ & $(.63)$ \\
\hline Surface Motive SM & .052 & .94 & .50 \\
& $(.02)$ & $(.988)$ & $(.72)$ \\
\hline Surface Strategy SS & .03 & 1.000 & .40 \\
& $(.02)$ & $(.998)$ & $(.57)$ \\
\hline
\end{tabular}

Note. $\mathrm{SRMR}=$ Standardized root mean squared residual; CFI $=$ comparative fit index

The first two columns report the indexes used to test the subscales unidimensionality. The standardized root mean squared residual (SRMR) values are all less than .08 and most of the comparative fit index (CFI) are greater than .95 (Cut-off) (Hu \& Bentler, 1998, 1999) except the surface motive (.94) that may be considered as acceptable. So, the single factor model fits the data very well. Therefore, the subscales are considered to be unidimensional.

The Cronbach's alphas are provided in the last column (Table 2). Biggs et al.'s (2001) related Cronbach's alphas are put between brackets for comparison purposes. Our Cronbach's alphas seem very poor and not so comparable to the original (Biggs et al., 2001). Most of them are less than .51 except the deep strategy $(\alpha=.59)$ which is close to the original value $(\alpha=.63)$. Still following Biggs et al.'s (2001) procedures and recommendations, the Cronbach's alpha was then computed to test the reliability of the two scales: surface and deep. They yielded the following values: .65 and .62 respectively. The table below (Table 3) shows the results:

Table 3. Reliability of scales $(\mathrm{N}=188)$

\begin{tabular}{l|c|c}
\hline Scales & Alpha $(\alpha)$ & N of Items \\
\hline Surface & .65 & 10 \\
\hline Deep & .62 & 10 \\
\hline
\end{tabular}

It should be admitted that the Biggs et al.'s acceptance rate in relation to Cronbach alpha appears to be very low. In the literature, .70 is generally suggested as the minimum (Tavakol, 2011). In this perspective, we tried to increase our Cronbach's alpha.

The SPSS output table labelled 'Cronbach's alpha if item deleted' (not given here), led our attempt to delete some items in order to improve scales reliability. The deletion of 3 items increased the deep scale 
Cronbach's alpha (From .62 to .65), whereas no item deletion was suggested to enhance the corresponding value in surface scale. Given those discrepancies, the process was discarded as it appeared to be unsuccessful. Nevertheless, from the Biggs et al.'s view, the surface scale $(\alpha=.65)$ seems more reliable than the Biggs et al.'s findings $(\alpha=.64)$ while the deep scale $(\alpha=.62)$ seems less reliable than the original findings $(\alpha=.73)$ (Biggs et al., 2001).

\subsection{Testing Biggs et al.'s Models (Confirmatory Factor Analysis)}

The confirmatory factor analysis was performed through the AMOS program. Instead of using conventionally recognized cut-off criteria of different fit indexes (rule of thumb) (Hu \& Bentler, 1999), the Biggs et al.'s procedures in relation to the assessment of the final version of the revised SPQ have inspired our practices, as we want also to validate their findings. In this line, we rely on CFI and SRMR to test the goodness of fit between the hypothesized model and the observed data. As mentioned above, the first model (items based) explores whether particular items correspond to the predicted cluster, while the second assesses the supposed dimensionality (dimensions based). It seems also worthwhile to mention that the estimated means were used to deal with missing values within our data (Field, 2009) and also that the maximum likelihood (ML) as default was employed to test both models (Biggs et al., 2001).

\subsubsection{The First Model (At the Items Level)}

To test the first model, the four subscales (DM, DS, SM, SS), were considered as latent variables on which load their respective five items (indicators or observed variables). A CFI values of .639 $(<.95)$ and the SRMR of .0897 (>.08) indicate a poor fit. So, the model does not adequately fit our data.

\subsubsection{The second model (At the Dimensions Level)}

In this model, the subscales represent the indicators or observed variables of the two latent factors which are Deep approach (DA) and Surface approach (SA). In other words, deep motive (dm) and deep strategy $(\mathrm{ds})$ are both indicators of DA, while surface motive ( $\mathrm{sm}$ ) and surface strategy (ss) correspond to the indicators of the SA. To make up those indicators, were lied on the parcelling technique by summing up the respective five items (Bandalos, 2002; Biggs et al., 2001). The estimation based on ML provided the following results: $\mathrm{CFI}=0.952$, and $\mathrm{SRMR}=0.047$. Based on the cut-offs, we can conclude that this second model fits our data very well.

\section{Discussions and Conclusions}

\subsection{Descriptives}

Considering on the one hand, the mean values in deep (34.89) and surface (24.50) scales, and on the other hand, their respective minimum (22 and 10) and maximum (47 and 43) values, it appears that the respondents scored higher in deep than surface scale. These findings are consistent with previous researchers mentioning deep approaches to learning as most dominant (Pottier et al., 2008; Mogre \& Amalba, 2014). Given that the students answered the questionnaire in relation to the study of their statistics course, their approaches are likely related to the specific context of statistics course for students in this department of Management, at Unikin. There is a need for research with students from various study contexts.

It is worthwhile to mention the significant positive correlation $(\mathrm{r}=.61)$ between deep and surface approaches. This confirms the view of both components as being not mutually exclusive (Biggs et al., 2001). In the same vein, Fryer et al. (2012) also reported a moderate positive correlation $(\mathrm{r}=.30)$ in a Japanese context. They related these findings to students' tendency to adopt a combination of both deep and surface approaches. Thereby, the current study has revealed that Congolese students might also adopt the same approach. In fact, the current version of the R-SPQ-2F does not explicitly assess an intermediate approach. In addition, the combination of approaches to learning was not identified by survey-based research studies but mostly by qualitative studies (Kember, 1996; Tan, 2011). So, to gain more insights in relation to SAL, a combination of techniques seems to be required (Martin, Dennehy, \& Morgan, 2013). Interviews - based research might be for instance a good point of departure to develop such specific scales. 
In relation to the same issue of correlation, it appears that the original work by Biggs et al. showed however a negative correlation between deep and surface factors (-.23) during the confirmatory factor analysis. Biggs et al. (2001) mentioned:

"These two higher order factors are then hypothesized as being negatively correlated since deep and surface approaches are envisaged as not commonly occurring in conjunction" (p.142).

So, this negative correlation related to the single constraint used during the confirmatory factor analysis. The mentioned statement has been however widely interpreted as 'deep and surface approaches are mutually exclusive constructs' (Kember, 1996; Tormey, 2014; Watkins \& Mboya, 1997; Xie, 2014). That gives rise to a debate and criticisms that might mainly be based on 'misinterpretations', given that Biggs and colleagues consider that the same student may flip from surface to deep approaches depending on his or her perceptions of the learning environments (Biggs et al., 2001; Leung et al., 2008). To avoid such misinterpretations, the current study deviated from Biggs et al.'s (2001) root, by deliberately omitting the use of constraints during confirmatory factor analysis. This decision rested on informative and evaluative reasons. Firstly, we wanted to discover the direction of relations that would emerge from Congolese data. Secondly, we have discursively tested the findings reporting a positive correlation as a particularity of the Japanese context (Fryer et al., 2012).

\subsection{Reliability}

The Cronbach's alpha for surface and deep scales yielded respectively .65 and .62. Compared to the first study using the French version of this instrument (.72 for deep and .70 for surface scale) (Coté et al., 2006) and to the recommended .70 (Tavakol, 2011), our Cronbach's alpha appear to be poor. From this point of view, the R-SPQ-2F represents an unreliable instrument which cannot be used to assess students' approaches to learning in a Congolese context. Nevertheless, it is important to note that when the original findings are considered (.64 and .73) (Biggs et al., 2001), our surface and deep scales appear to be respectively more and less reliable. Unlike previous studies (Biggs et al., 2001; Pottier et al., 2008), the deep scale appears to be the least reliable. In this way, these findings deviate from those reporting that the surface scale is not only the less portable but also the less reliable scale across cultures (Richardson, 1994). This might be explained by some cultural aspects such as schooling language, interpretation of items that are not addressed in the current study.

When the internal consistency of sub-scales was examined, the findings contrasted the original results as shown in table 2 (.28 for DM, .59 for DS, .50 for SM, and .40 for SS). The subscales Cronbach's alpha might be affected by the small number of items (5 per subscale) (Field, 2009; Schmitt, 1996). On the other side, there is an argument from the literature asserting that scales-based analysis improves the reliability and the construct validity of the R-SPQ-2F better than subscales-based (Xie, 2014). In the same line, Justicia and co-workers (2008) also suggested that the R-SPQ-2F, in terms of factor structure, should be used only to determine its main scales (deep and surface approaches) (Justicia et al., 2008). So, in connection with those findings, the current results illuminate the fact that the two main scales of the R-SPQ-2F are reasonably reliable. Likewise, we recommend further researches to focus on the reliability of the main scales. Nevertheless, further refinement of the deep scale through a meticulous examination of each item would be a useful task.

\subsection{Construct Validity}

The confirmatory factor analysis tested the Biggs et al.'s (2001) hypothesized models. Consistent with previous findings in the literature (Fryer et al., 2012), the first model (items-based) appeared to be a poor model $(\mathrm{CFI}=0.639$ and $\mathrm{SRMR}=0.090)$. It is generally recommended to improve the model fit by adding supplementary constraints or by removing items affecting the model inadequacy (Hu \& Bentler, 1999). Numerous researchers have relied on this process. Bliuc et al., (2011a) for instance, have reduced items to 10 instead of 20 to improve the model fit. Similarly, Fryer and colleagues (2012) removed 4 items as they were found to be problematic during their respondents' interviews. Other different models were also mentioned in the literature (Justicia et al., 2008; Phan \&Deo, 2007). However, the present study intended to consistently follow Biggs et al.'s sequences of the confirmatory factor analysis. In this perspective, it appeared important to test the second model. Moreover, it is generally recommended to test more than one model in the same study (Jackson, Gillaspy, \& Purc-Stephenson, 2009). 
In the second model, it was hypothesized that two latent factors, DA and SA are composed of motives and strategies which are the indicators or manifest variables. This model fitted adequately the data $(\mathrm{CFI}=0.952$, and $\mathrm{SRMR}=0.047)$. These findings are in connection with other results in the literature demonstrating that the second model is a better model fit than the first (Biggs et al., 2001; Fryer et al., 2012). The parcelling may have positively affected the goodness of model fit. Indeed, several researchers acknowledged the benefits of this statistic technique, particularly if the items are unidimensional (Bandalos, 2002; Little, Rhemtulla, Gibson, \& Schoemann, 2013). Additionally, Little et al. (2013) suggest relying on the parcelling technique, when the research goal relates to the understanding of dimensions rather than items (Little et al., 2013). As expected, the instrument appears to be validly constructed. Our results, in line with previous findings, support the assertion that the R-SPQ-2F constructs are valid to assess SAL. We strongly suggest however, the exploration of other types of validity, such as the external construct validity (Xie, 2014), to extend the current view of SAL in an African French speaking setting.

\subsection{Conclusion}

This study represents an initial attempt to validate the R-SPQ-2F in a Congolese context. The results have demonstrated that the R-SPQ-2F represents a valid and reasonably reliable instrument. However, these psychometric properties are subjected to specific conditions, particularly the validity at the dimensions level and the reliability of the main scales. Our results may also have hidden a number of items' problems. To address these points, further examinations of items through an exploratory factor analysis are needed. It seems also important to mention that the sample size (188 students), as well as the context restriction (University, faculty, and a specific course) might affect the findings especially given the doubtful reliability $(\alpha<.70)$ (Tavakol, 2011). Therefore, some cautions are needed in the use of the instrument to assess Congolese SAL. Furthermore, the cultural dimension within and across Congolese regions should be considered (McSweeney, 2002). We strongly recommend further evidence of validation by investigating data from a large sample of students from various universities and provinces in Congo.

Acknowledgements. This research was supported by grants from the Marc Vervenne fund (KU Leuven) and Fondation Neunez (Bruxelles). We are grateful to David Kember and John Biggs who allowed us to use their R-SPQ-2F. We gratefully thank Olivier, Dr Busaki and Dr Xiao-Li for their comments and suggestions. We are indebted to Dr Mandosi, Ingwa, Mulanga, and Masamuna who have facilitated data collection at UNIKIN and UCC. Thanks to all students who have accepted to fill out the questionnaire.

Conflict of Interest. The authors declare that there is no conflict of interests regarding the publication of this paper.

\section{References}

1. Asikainen, H., Parpala, A., Lindblom-Ylänne, S., Vanthournout, G., \& Coertjens, L. (2014). The development of approaches to learning and perceptions of the teaching-learning environment during bachelor level studies and their relation to study success. Higher Education Studies, 4(4), 24-36.

2. Bandalos, D. L. (2002). The effects of item parceling on goodness-of-fit and parameter estimate bias in structural equation modeling. Structural Equation Modeling, 9(1), 78-102.

3. Beatty, P.C. \& Willis, G.B.(2007). Research synthesis: the practice of cognitive interviewing. Public Opinion Quarterly, 71(2), 287-311.

4. Biggs, J. B. (1987). Student approaches to learning and studying. Melbourne: Australian Council for Educational Research.

5. Biggs, J., Kember, D., \& Leung, Y.P. (2001). The revised two-Factor study process questionnaire: R-SPQ-2F. British Journal of Educational Psychology, 71, 133-149. 
6. Bliuc, A.M., Ellis, R.A., Goodyear, P., \& Hendres, D.M. (2011a). The role of social identification as university student in learning: Relationships between students' social identity, approaches to learning and academic achievement. Educational Psychology, 31(5), 559-574.

7. Bliuc,A.M., Ellis, R.A., Goodyear, P., \& Hendres, D.M.(2011b). Understanding student learning in context: Relationships between university students' social identity, approaches to learning, and academic performance. European Journal of Psychology and Education, 26, 417-433.

8. Brancato, G., Macchia, S., Murgia, M., Signore, M., Simeoni, G., Blanke, K., Körner, T., Nimmergut, A., Lima, P., Paulino, R., \&Hoffmeyer-Zlotnik, J. (2006). Handbook of Recommended Practices for Questionnaire Development and Testing in the European Statistical System. Retrieved from https://www.istat.it/files/ 2013/12/Handbook_questionnaire_development_ $\neg 2006 . p d f$.

9. Chan, C. K. K., \& Rao, N. (2009). Revisiting the Chinese learner: Changing contexts, changing education. (1st ed.). University of Hong Kong: Springer Comparative Education Research Centre.

10.Coertjens, L., Vanthournout, G., Lindblom-Ylänne, S., \& Postareff, L. (2016). Understanding individual differences in approaches to learning across courses: A mixed method approach. Learning and Individual Differences, 51, 69-80.

11.Coté, D. J., Graillon, A., Waddell, G., Lison, C., \& Noel, M. F. (2006). L'approche d'apprentissage dans un curriculum médical préclinique basé sur l'apprentissage par problèmes.[Medical students' approaches to learning based on problem-solving performances]. Pédagogie Médicale, 7, 201-212.

12.Desimone, L. M., \& Le Floch, K. C. (2004). Are we asking the right questions? Using cognitive interviews to improve surveys in education research. Education Evaluation and Policy Analysis, 26(1), 1-22.

13.Driscoll, M. P. (2005). Psychology of Learning for Instruction(3rded.). New York: Pearson Education.

14.Elen, J., \& Lowyck, J. (2000). Instructional metacognitive knowledge: A qualitative study on conceptions of freshmen about instruction. Journal of Curriculum Studies, 32, 421-444.

15.Entwistle N. J., \& Peterson, E. R. (2004). Conceptions of learning and knowledge in higher education: Relationships with study behavior and influences of learning environments. International Journal of Educational Research, 41, 407-428.

16.Entwistle, N. J., \& Ramsden, P. (1983). Understanding student learning. London: Croom Helm.

17.Entwistle, N., Tait, H., \& McCune, V. (2000). Patterns of response to approaches to studying inventory across contrasting groups and contexts. European Journal of Psychology of Education, 15(1), 33-48.

18.Field, A. (2009). Discovering statistics using SPSS (3rd ed.). Los Angeles: Sage Publications.

19.Fryer, L. K., Ginns, P., Walker, R. A. \& Nakao, K. (2012). The adaptation and validation of the CEQ and the R-SPQ-2F to the Japanese tertiary environment. Educational Psychology82, (4), 549-563.

20.Gijbels, D., Segers, M.\& Struyf, E. (2008). Constructivist learning environments and the (im) possibility to change students' perceptions of assessment demands and approach to learning. Instructional Science, 32(5,6), 431-443.

21.Gijbels, D., Coertjens, L., Vanthournout, G., Struyf, E., \& Van Petegem, P. (2009). Changing students' approaches to learning: A two-year study within a university teacher training course.EducationalStudies, 35(5), 503-513.

22.Gijbels, D., Van de Watering, G., Dochy, F. \& Van den Bossche, P. (2005). The relationship between students' approaches to learning and learning outcomes. European Journal of Psychology of Education, 20(4), 327-341.

23.Hu, L-T., \& Bentler, P. M. (1998). Fit indices in covariance structure modeling: Sensitivity to underparameterized model misspecification. Psychological Methods, 3, 424-453.

24.Hu, L-T., \& Bentler, P.M. (1999). Cutoff criteria for fit indices in covariance structure analysis: Conventional criteria versus new alternatives. Structural Equation Modeling, 6, 1-55.

25.Jackson, D. L., Gillaspy, J. A., \& Purc-Stephenson, R. (2009). Reporting practices in confirmatory factor analysis. Psychological Methods, 14(1), 6-23.

26.Justicia, F., Pichardo, M. C., Cano, F., Berbén, A. B. G., \& De la Fuente, J. (2008). The revised two-factor study process questionnaire (R-SPQ-2F): Exploratory and confirmatory factor analysis at item level. European Journal of Psychology of Education, 13(3), 355-372.

27.Kember, D. (1996). The intention to both memorize and understand: Another approach to learning. Higher Education, 31, 341-354. 
28.Kember, D. (2000). Misconceptions about the learning approaches, motivation and study practices of Asian students. Higher Education, 40, 99-121.

29.Kember, D., \& Gow, L. (1990). Cultural specificity of approaches to study. British Journal of Educational Psychology, 60, 356-363.

30.Kember, D., \& Leung, D. Y. P. (1998). The dimensionality of approaches to learning: An investigation with confirmatory factor analysis on the structure of the SPQ and LPQ. British Journal of Educational Psychology, 68, 395-407.

31.Kember, D., \& Watkins, D. (2010). Approaches to learning and teaching by the Chinese. In M. H. Bond (Ed.), Oxford handbook of Chinese psychology (pp. 169-186). Oxford: Oxford University Press.

32.Kember, D., Wong, A., \& Leung, D. Y. P. (1999). Reconsidering the dimensions of approaches to learning. British Journal of Educational Psychology, 69, 323-343.

33.Leung, D.Y.P, Ginns, P., \& Kember, D. (2008). Examining the cultural specificity of approaches to learning in universities in Hong Kong and Sydney. Journal of Cross-Cultural Psychology, 39(3), 251-266.

34.Little, T. D. , Rhemtulla, M., Gibson, K., \&Schoemann, A. M. (2013). Why the items versus parcels controversy needn't be one. Psychological Methods, 18(3), 285-300.

35.Manikutty, S., Anuradha, N.S., \& Hansen, K. (2007). Does culture influence learning styles in higher education? International Journal of Learning and Change, 2(1), 70-87.

36.Martin, L. R., Dennehy, R., \& Morgan, S. (2013). Unreliability in student evaluation of teaching questionnaires: Focus groups as an alternative approach. Organization Management Journal, 10(1), 66-74.

37.Marton, F., \& Säljö, R. (1976). On qualitative differences in learning outcome as a function of the learner's conception of the task. British Journal of Educational Psychology, 46(2), 115- 127.

38.Marton,F.,\&Säljö,R. (1984). Approaches to learning. In F. Marton, D. Hounsell, \& N. Entwistle (Eds.), The experience of learning (pp. 39-58). Edinburgh: Scottish Academic Press.

39.McSweeney, B.(2002). Hofstede's model of national cultural differences and their consequences: A triumph of faith - a failure of analysis. Human Relations, 55(1), 89-118.

40.Meyer, J.H.F., \& Muller, M. W. (1990). Evaluating the quality of student learning. Studies in Higher Education, $15(2), 131-154$.

41.MINESU (2011). Plan strategique de l'enseignement supérieur et universitaire de la République Démocratique du Congo [Congolese higher education strategic plan]. Kinshasa: Minesu.

42.Mogre, V., \& Amalba, A. (2014). Assessing the reliability and validity of the Revised Two factor study process questionnaire (R-SPQ-2F) in Ghanaian medical students. Journal of Educational Evaluation for Health Professions, 11(19). Retrieved from https://doi.org/10.3352/jeehp.2014.11.19.

43.Mogre, V., \& Amalba, A. (2015). Approaches to learning among Ghanaian students following a PBL-based medical curriculum. Education in Medicine Journal, 7(1), 38-44.

44.Parpala, A., Lindblom- Ylänne, S., Komulainen, E., \& Entwistle, N. (2013). Assessing students' experiences of teaching- learning environments and approaches to learning: Validation of a questionnaire in different countries and varying contexts. Learning Environment Research, 16, 201-215.

45.Phan, H.P., \& Deo,B. (2007). The revised learning process questionnaire: A validation of a western model of students study approaches to pacific context using confirmatory factor analysis. British Journal of Educational Psychology, 77, 719-139.

46.Pottier, P., Derkinderen, P., Barrier, J., Sevin, M., Rogez, J. M., \& Planchon, B. (2008). Etude descriptive des pratiques d'apprentissage d'étudiants en quatrième année de médecine dans une faculté française et de leurs performances à résoudre un problème [Descriptive study of learning practices and their problem-solving performances in fourth year medical students]. Pédagogie Médicale, 9(2), 70-82.

47.Richardson, J.T.E. (1994). Cultural specificity of approaches to studying in higher education: A literature survey. Higher Education, 27, 449-468.

48.Richardson, J.T.E.(2004). Methodological issues in questionnaire-based research on student learning in higher education. Educational Psychology Review, 16, 347-358.

49.Richey, R. C., Klein, J. D., \& Tracey, M. W. (2011). The instructional design knowledge base: Theory, research, and practice. New York, NY: Routledge.

50.Säljö, R. (2004). Learning and technologies, people and tools in coordinated activities. International Journal of Educational Research, 41, 489-494. 
51.Schendel, R. (2014, December). "Some kind of disorder": The negative effects of modularization on student learning in Rwandan university context. Paper presented at the Society of Research into Higher Education Conference, South Wales, UK.

52.Schmitt, N. (1996). Uses and abuses of coefficient alpha. Psychological Assessment, 8(4), 350-353.

53.Tan, P-L. (2011). Towards a culturally sensitive and deeper understanding of "rote learning" and memorization of adult learners. Journal of Studies in International Education, 15(2), 124-145.

54.Tavakol, M. D. R. (2011). Making sense of Cronbach's alpha. International Journal of Medical Education, 2, 5355 .

55.Tormey, R. (2014). The centre cannot hold: untangling two different trajectories of the 'approaches to learning' framework. Teaching in Higher Education, 19(1), 1-12.

56.Watkins, D., \& Mboya, M. (1997). Assessing the learning processes of black African students. Journal of Psychology, 131(6), 632-640.

57.Weston, R. \& Gore Jr., P.A. (2006). A Brief guide to structural equation modeling. The Counseling Psychologist, $34(5), 719-751$.

58.Xie, Q. (2014). Validating the revised two-factor study process questionnaire among Chinese university students. International Journal of Educational and Psychological Assessment, 16(1), 4-20. 